\title{
Multifunctional Materials for OFETs, LFETs and NIR PLEDs
}

\author{
T. T. Steckler, ${ }^{a+}$ M. Lee,${ }^{b+c}$ Z. Chen, ${ }^{b+\S}$ O. Fenwick,${ }^{c+}$ M. R. Andersson, ${ }^{* a}$ F. Cacialli*c and H. Sirringhaus ${ }^{* b}$
}

A family of phthalimide-thiophene copolymers with linear or branched alkyl chains attached to the imide nitrogen have been synthesized. Their optical and electronic properties were investigated along with their applications in OFETs and LFETs. The phthalimide-thiophene copolymer having a $\mathrm{C}_{16}$ straight alkyl chain on the phthalimide yielded the highest mobilities and PLQE with hole and electron mobilities of $1 \times 10^{-3} \mathrm{~cm}^{2} \mathrm{~V}^{-1} \mathrm{~s}^{-1}$ for holes and $1 \times 10^{-2} \mathrm{~cm}^{2} \mathrm{~V}^{-1} \mathrm{~s}^{-1}$ for electrons with a PLQE of $\sim 28 \%$ in the solid state. Since these polymers are ambipolar and emissive, they have proven to be useful for applications as a host material for NIR PLEDs. In this study a $1 \%$ loading of NIR emitting DAD segments based on bisthienyl(thiadiazoloquinoxaline) or bisthienyl(benzotriazolothiadiazole) were incorporated into the phthalimide-thiophene polymerization. Using the branched $\mathrm{CH}\left(\mathrm{C}_{8} \mathrm{H}_{17}\right)_{2}$ alkyl chain on the host phthalimide-thiophene copolymer combined with the bisthienyl(benzotriazolothiadiazole) emitter resulted in the most efficient single layer NIR emitting PLED to date with an EQE of $0.27 \%$ emitting at $885 \mathrm{~nm}$.

\section{Introduction}

Conjugated polymers have shown great potential as the active components of organic field-effect transistors (OFETs) $)^{1,2}$ and organic light-emitting diodes (OLEDs). ${ }^{3,4}$ Some of the major advantages of conjugated polymers is their solution processability at low temperatures, flexibility, low-cost and suitability to form large area surfaces. ${ }^{5}$ Ambipolar materials offer advantages of using a single organic material for producing both p- and n-type transistors, allowing for the simplified manufacturing of CMOS-type circuits from a single organic material. ${ }^{6}$ Some of the best performing polymer OFET materials offer mobilities in the range of $0.1-8 \mathrm{~cm}^{2} \mathrm{~V}^{-1} \mathrm{~s}^{-1}$ for p-type and $0.1-2 \mathrm{~cm}^{2} \mathrm{~V}^{-1} \mathrm{~s}^{-1}$ for n-type. ${ }^{1,7-9}$ While some of these polymers are ambipolar, only a few have fully balanced electron and hole transport. The best performing ambipolar polymers in terms of mobility usually contain imide type structures such as 3,6dithiophen-2-yl-2,5-dialkylpyrrolo[3,4-c]pyrrole-1,4-dione (DPP), or similar derivatives, with the best results seen to date coming from a DPP based polymer having hole and electron mobilities of $3.97 \mathrm{~cm}^{2} \mathrm{~V}^{-1} \mathrm{~s}^{-1}$ and $2.20 \mathrm{~cm}^{2} \mathrm{~V}^{-1} \mathrm{~s}^{-1}$, respectively. ${ }^{8}$ Materials with good and balanced ambipolar mobilities as well as high luminescence yield would enable fabrication of light-emitting filed-effect transistors (LEFETs). The advantage of LEFETs is their high recombination efficiency, ${ }^{10}$ the ability to use a much simpler circuit structure than for OLEDs, fine control of the emission zone depending on the gate voltage ( $\left.V_{\mathrm{g}}\right)$ relative to the source and drain voltage $\left(\mathrm{V}_{\mathrm{s}} / \mathrm{V}_{\mathrm{d}}\right),{ }^{11,12}$ and improved light out-coupling since ITO is not needed. ${ }^{13}$ This allows for entry into various lighting, display and other organic optoelectronic applications. While initial work on the development of LEFETs started with a small molecule emitter based on tetracene, ${ }^{14}$ work in this field has continued with both small molecules and polymers. ${ }^{11,13,15-17}$ To date, poly(9,9dioctylfluorenealt-benzothiadiazole) (F8BT) is one of the most widely studied polymers in LEFET devices, and is the best performing polymer LEFET material with an EQE $>8 \%$ along with hole and electron mobilities on the order of $10-3 \mathrm{~cm}^{2} \mathrm{~V}^{-1} \mathrm{~s}^{-1}$ and $10-4 \mathrm{~cm}^{2} \mathrm{~V}^{-1} \mathrm{~s}^{-1}$ respectively. ${ }^{10,13}$

Since conjugated oligomers and polymers incorporating imide-type moieties have shown success as high mobility materials, thus we became interested in the phthalimide based polymers developed by Watson et al., which showed a high hole mobility of $\sim 0.2$ $\mathrm{cm}^{2} \mathrm{~V}^{-1} \mathrm{~s}^{-1}$ when copolymerized with a dialkoxybithiophene donor, however, there was no mention of electron mobility or ambipolar behavior. ${ }^{9}$ In order to probe these materials in more detail, we first started out with the simple preparation and characterization of the phthalimide thiophene copolymer P1. With the discovery that this polymer was both luminescent and showed ambipolar behavior led to further development of this system, both as an OFET and LEFET material.

After demonstrating the usefulness of dioctylfluorene as a host material in NIR and red emitting PLEDs, ${ }^{18}$ we have subsequently decided to investigate phthalimide based polymers as new host materials based on their ambipolar and luminescent properties. While most research in OLEDs/PLEDs deals with visible or white light emission, ${ }^{3,19}$ relatively little focus is on NIR emission, ${ }^{20}$ especially from conjugated polymers. ${ }^{15,21-24}$ Polymer emitters that emit beyond $850 \mathrm{~nm}$ are usually in the $0.02-0.05 \%$ range for EQE. ${ }^{21,23,24}$ In this study we investigated a phthalimide-thiophene host polymer combined with two low gap donor-acceptor-donor (DAD) emitters, one based on the LBPP-1 DAD (14, Figure 1) that was studied previously, ${ }^{18}$ and a novel DAD emitter (13) based on the bisthienyl(benzotriazolothiadiazole) unit first introduced by the Grimsdale group, ${ }^{25}$ and further developed by the Reynolds group. ${ }^{26}$ Our reason for using the benzotriazolothiadiazole acceptor is based on the fact that oligomers and polymers containing the benzotriazole unit have proven to be quite emissive. ${ }^{26,27}$ Having the benzotriazole moiety in the low gap emitter should hopefully improve the NIR emission.

\section{Experimental}


Please see the supporting information for all synthesis and materials characterization details.

\section{Results and discussion}

\section{Polymers for OFETs and LFETs}

The synthesis of the phthalimide monomers (Scheme S1) followed the synthetic procedures described in literature. ${ }^{9}$ For monomer $\mathbf{5}$, the key is the formation of 9-aminoheptadecane (3). Following the Gabriel synthesis of amines, 9-tosylheptadecane (1) was reacted with potassium phthalimide to form $\mathrm{N}$-(heptadecane-9-yl)phthalimide $(\mathbf{2}, 50 \%)$. Cleavage of 2 with ethanolamine afforded the desired amine $\mathbf{3}$ in quantitative yield. Then 3,6-dibromophthalicanhydride was condensed with $\mathbf{3}$ or the commercially available dodecylamine and hexadecylamine to form monomers $5(59 \%), 6(85 \%)$ and $7(89 \%)$. Stille polymerization (Figure 1 \& Scheme S3) of monomers 5-7 with 2,5-Bis(trimethylstannyl)thiophene $(\mathbf{A})$ in toluene yielded polymers $\mathbf{P 1}\left(\mathrm{R}=\mathrm{C}_{12} \mathrm{H}_{25}, 54 \%\right), \mathbf{P 2}(\mathrm{R}=$ $\left.\mathrm{C}_{16} \mathrm{H}_{33}, 62 \%\right)$ and $\mathbf{P 3},\left(\mathrm{R}=\mathrm{CH}\left(\mathrm{C}_{8} \mathrm{H}_{17}\right)_{2}, 92 \%\right)$. Due to the formation of insoluble polymer inside the reaction flasks of $\mathbf{P 1}$ and $\mathbf{P 2}$, the polymerizations were stopped after 20 and 12 minutes respectively, whereas $\mathbf{P 3}$ was polymerized for 2 days. After polymerization the polymers were precipitated into methanol $(\mathrm{MeOH})$, collected by filtration, dissolved in $\sim 100 \mathrm{~mL}$ of chloroform $(\mathrm{CF})$ and stirred vigorously with sodium diethyldithiocarbamate trihydrate $\left(\sim 5 \mathrm{~g}\right.$ in $\left.100 \mathrm{~mL} \mathrm{H}{ }_{2} \mathrm{O}\right)$ overnight to remove any residual catalyst. Then the $\mathrm{CF}$ /polymer solution was washed with water $(3 \mathrm{X})$, concentrated, precipitated into $\mathrm{MeOH}$ and collected by filtration. The polymer was then subjected to Soxhlet extraction with $\mathrm{MeOH}$, acetone, hexane and $\mathrm{CF}$. The CF fraction was concentrated, precipitated in to $\mathrm{MeOH}$ and a bright orange solid was collected by filtration for P1-2 and an orangish-yellow fiber like solid for P3. The lower yields and molecular weights of polymers P1-2 $(6.5 \mathrm{~kg} / \mathrm{mol}, 9.4 \mathrm{~kg} / \mathrm{mol})$ (Table S1) compared to P3 (40 kg/mol) can be explained by the use of the straight, less solubilizing $\mathrm{C}_{12}$ and $\mathrm{C}_{16}$ alkyl chains in P1-2 versus the branched $\mathrm{CH}_{(}\left(\mathrm{C}_{8} \mathrm{H}_{17}\right)_{2}$ alkyl chain used in $\mathbf{P 3}$.
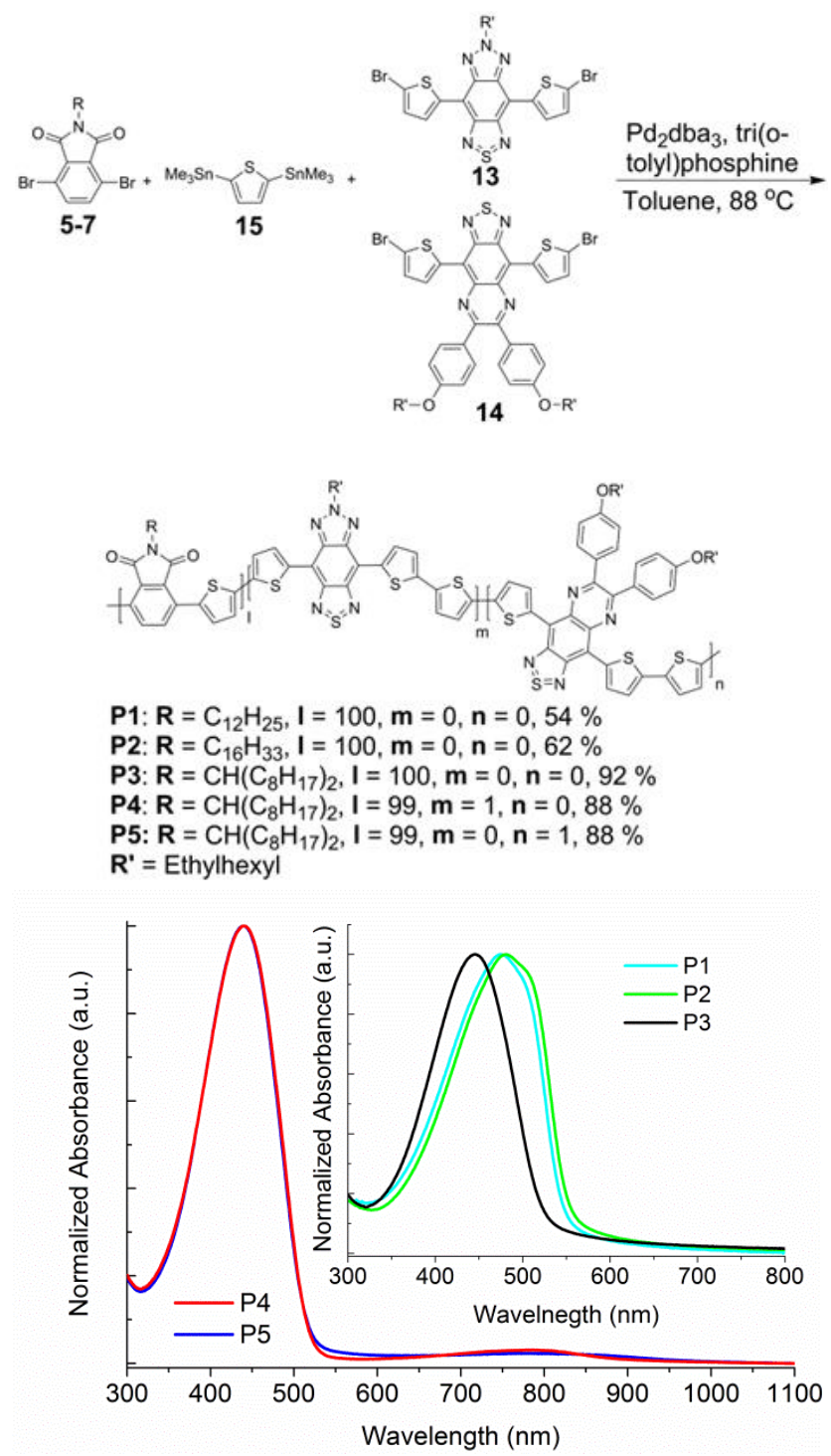
Figure 1. Top: Synthesis of phthalimide-thiophene copolymers P1-3 and NIR-emitting polymers P4 and P5. Bottom: UV-Vis-NIR Absorption Spectra for polymer films P1-5.

Initial characterization of $\mathbf{P 1}$ shows a $\lambda_{\max }$ of $475 \mathrm{~nm}$ and an onset of absorption at $546 \mathrm{~nm}$ corresponding to an optical band gap of $2.27 \mathrm{eV}$ (Figure 1). The highest occupied molecular orbital (HOMO) and lowest unoccupied molecular orbital (LUMO) levels were determined by square-wave voltammetry (Figure S1 \& Table S2). All potentials were measured relative to the Fc/Fc+ redox couple where the onset for oxidation and reduction were used for the HOMO and LUMO respectively. The HOMO/LUMO values were determined using the conversion of HOMO/LUMO $=-\left(\mathrm{E}_{\mathrm{ox} / \mathrm{red}}+5.13\right) \mathrm{eV} .{ }^{28}$ This method was applied to all polymers in this study. P1 has a HOMO of $5.96 \mathrm{eV}$ and a LUMO of $3.39 \mathrm{eV}$ corresponding to an electronic band gap of $2.57 \mathrm{eV}$. Since P1 was observed to be fluorescent, photo-luminescence (PL) measurements were performed on a thin film and showed a PL quantum yield (PLQE) of $\sim 20 \%$ (Figure S2).

a)

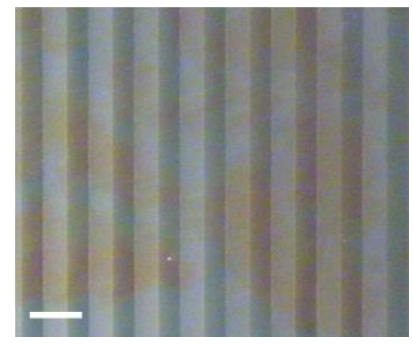

b)

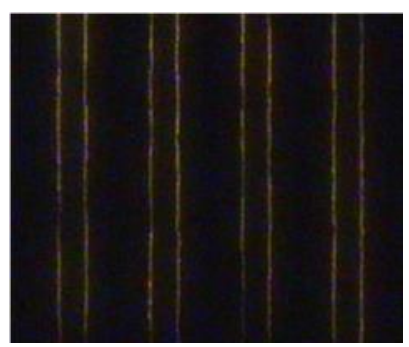

c)

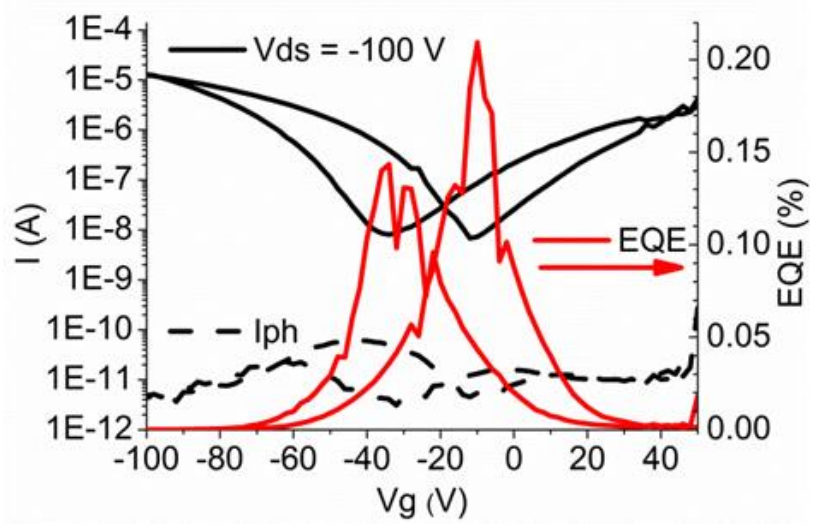

Figure 2. (a) Digital camera image of a typical FET based on P1 under illumination showing source and drain electrodes (W = 1 $\mathrm{cm}, \mathrm{L}=20 \mu \mathrm{m}$ ). The scar bar corresponds to $40 \mu \mathrm{m}$. (b) The digital camera image of the same FET at the same position as (a) recorded in the dark and under the bias condition of $\mathrm{V}_{\mathrm{gs}}=100 \mathrm{~V}$ and $\mathrm{V}_{\mathrm{ds}}=200 \mathrm{~V}$. (c) Transfer characteristics of a light-emitting FET based on $\mathbf{P 1}$ and the corresponding photocurrent measured with a photodiode mounted on top of the device and the calculated external quantum efficiencies (EQE).

Due to the reasonable PLQE, LEFETs were fabricated from as-spun $\mathbf{P 1}$ and showed clear ambipolar characteristics exhibiting saturation hole mobility $\mu_{h} \sim 4 \times 10^{-3} \mathrm{~cm}^{2} \mathrm{~V}^{-1} \mathrm{~s}^{-1}$ and electron mobility $\mu_{e}$ in the range of $2 \times 10^{-3} \mathrm{~cm}^{2} \mathrm{~V}^{-1} \mathrm{~s}^{-1}$ for devices of channel length $\mathrm{L}=20 \mu \mathrm{m}$ (Figure $2 \&$ Table 1). The electron mobility being only half of the hole mobility can be related to the higher lying LUMO (3.39 eV) and the difficulty of charge injection from gold electrodes $(5.1 \mathrm{eV})$ (Figure S1). As a consequence of ambipolar charge transport, we observed a yellow light emission during the operation of FETs based on P1 (Figure 2a,b) when we employed a thin and semi-transparent gold $(\sim 8 \mathrm{~nm}$ thick $)$ layer as the gate. Due to the imbalanced hole and electron mobility, the light-emission zone is close to the electron-injecting electrode for a wide range of bias conditions. By placing an optical fiber connected to a spectrometer directly on top of the gold top gate, we recorded the electroluminescence from P1 transistors, which is very similar to its PL (Figure S2). By placing a silicon photodiode directly on top of the semitransparent gold gate, we measured the photocurrents $I_{p h}$ simultaneously when we measured the transfer $I-V$ curve (Figure 2c). From the ratio between the photocurrent and the drain current, taking into account the photodiode sensitivity, ${ }^{29}$ we estimated the external quantum efficiency (EQE) of the electroluminescence from P1 light-emitting transistors to be up to $\sim 0.2 \%$ (Figure 2c).

The EQE from P1 FETs is significantly smaller, even though within the same order of magnitude, compared to EQE from FETs based on poly(9,9-dioctylfluorene-alt-benzothiadiazole) (F8BT). ${ }^{17}$ This lower EQE can be understood as the combined consequence 
from its lower PLQE and the imbalanced ambipolar mobilities. Another possible reason for the lower performance could be attributed to the presence of stannyl or bromo end-groups, since stannyl end-groups can be seen at 0.43 ppm in the NMR spectra (Figure S5). There is also an initial $\sim 3.3 \%$ weight loss seen between $260-330{ }^{\circ} \mathrm{C}$ in the TGA, corresponding to the loss of a trimethylstannyl and bromo end-group per polymer chain (Figure S6). No transitions were seen in the DSC, but due to the initial weight loss seen in the TGA, the DSC was only run until $250{ }^{\circ} \mathrm{C}$. It is highly likely that this polymer is semi-crystalline based on the AFM images seen in Figure S8. To evaluate this polymer and the other polymers (P2-3) used in the LEFET and OFET study further, X-ray diffraction (XRD) was performed on drop-cast films of P1-3 (Figure S9-10). P1 drop cast film shows a first-order diffraction maxima at an intermediate angle and an amorphous halo at wider angles. Upon annealing at $290{ }^{\circ} \mathrm{C}$ for 30 minutes, first- and second-order diffraction maxima were seen with a similar amorphous halo at wider angles. These first- and second-order diffraction maxima point towards short-range lamellar ordering as seen for similarly structured polymers. ${ }^{9}$

Based on the these results, we sought to improve the molecular weight in hopes of improving the mobility values since the $\mathrm{M}_{\mathrm{n}}$ of P1 was only $6.5 \mathrm{~kg} / \mathrm{mol}$, corresponding to a degree of polymerization (DP) of $\sim 16$. Our first thought was to use a branched (heptadecane-9-yl) alkyl chain as seen in Scheme 1, which should improve the solubility and hopefully increase the PL of the polymer. It was at this stage that we started to investigate these materials as host materials for NIR PLEDs, initially starting with P3, which will be discussed later.

Due to the increased solubility of $\mathbf{P 3}$ using the branched $\mathrm{CH}\left(\mathrm{C}_{8} \mathrm{H}_{17}\right)_{2}$ side chain, the polymerization reaction did not precipitate during the reaction and yielded a polymer with a $\mathrm{M}_{\mathrm{n}}$ of $40 \mathrm{~kg} / \mathrm{mol}$ corresponding to a DP of 88 . While a much higher $\mathrm{M}_{\mathrm{n}}$ and $\mathrm{DP}$ compared to P1 was obtained, the $\lambda_{\max }$ blue-shifted $30 \mathrm{~nm}$ to $445 \mathrm{~nm}$ (Figure 1) while the onset of absorption also blue-shifted, corresponding an optical band gap of $2.37 \mathrm{eV}, 0.1 \mathrm{eV}$ higher than P1. Based on the absorption spectra seen in Figure 1, the branched alky chain has inhibited some of the ordering and packing in the solid state compared to the straight alkyl chains, so it is surprising that the luminescent properties of P3 also decreased significantly, showing a PLQE of only $\sim 3 \%$. Closer evaluation of the HOMO/LUMO levels (Figure S1, Table S2) of P3 shows a LUMO of $3.50 \mathrm{eV}$, which is similar to P1 (3.39 eV), however the HOMO is much deeper for $\mathbf{P 3}(6.31 \mathrm{eV})$ compared to $\mathbf{P 1}(5.96 \mathrm{eV})$.

FETs fabricated from annealed $\left(300^{\circ} \mathrm{C}\right) \mathbf{P 3}$ showed unbalanced ambipolar characteristics exhibiting saturation hole mobility $\mu_{h}$ $\sim 8 \times 10^{-5} \mathrm{~cm}^{2} \mathrm{~V}^{-1} \mathrm{~s}^{-1}$ and electron mobility $\mu_{e}$ in the range of $1 \times 10^{-3} \mathrm{~cm}^{2} \mathrm{~V}^{-1} \mathrm{~s}^{-1}$ for devices of channel length $\mathrm{L}=20 \mu \mathrm{m}(\mathbf{F i g u r e} \mathbf{S 4}$ \& Table 1). The hole and electron mobilities are about doubled compared to the as-spun $\left(100{ }^{\circ} \mathbf{C}\right)$ devices (Table S3 \& Figure S4). The large decrease in hole mobility can be related to the deeper lying HOMO $(6.31 \mathrm{eV})$ and the difficulty of charge injection relative to $\mathbf{P 1}$ from the gold electrodes $(5.1 \mathrm{eV})$. Due to the higher molecular weight and greater thermal stability of $\mathbf{P 3}$ relative to $\mathbf{P 1}$ and P2 (Figure S5), DSC measurements of P3 (Figure S6) showed a melt with a $\mathrm{T}_{\mathrm{m}}$ of $255{ }^{\circ} \mathrm{C}$ and upon cooling a $\mathrm{T}_{\mathrm{c}}$ of $200{ }^{\circ} \mathrm{C}$, indicative of a semi-crystalline polymer. However, XRD analysis of a drop-cast film of $\mathbf{P 3}$ annealed at $290{ }^{\circ} \mathrm{C}$ for 30 minutes (Figure S10) showed no diffraction maxima at intermediate angles and only an amorphous halo at wider angles. The lack of order and packing for $\mathbf{P 3}$ can be correlated to the differences in the HOMO/LUMO values, UV-Vis absorption spectra and the poor FET performance. While the branched side chain allowed for better solubility and improved molecular weight, it lead to decreased hole mobility, PLQE and order.
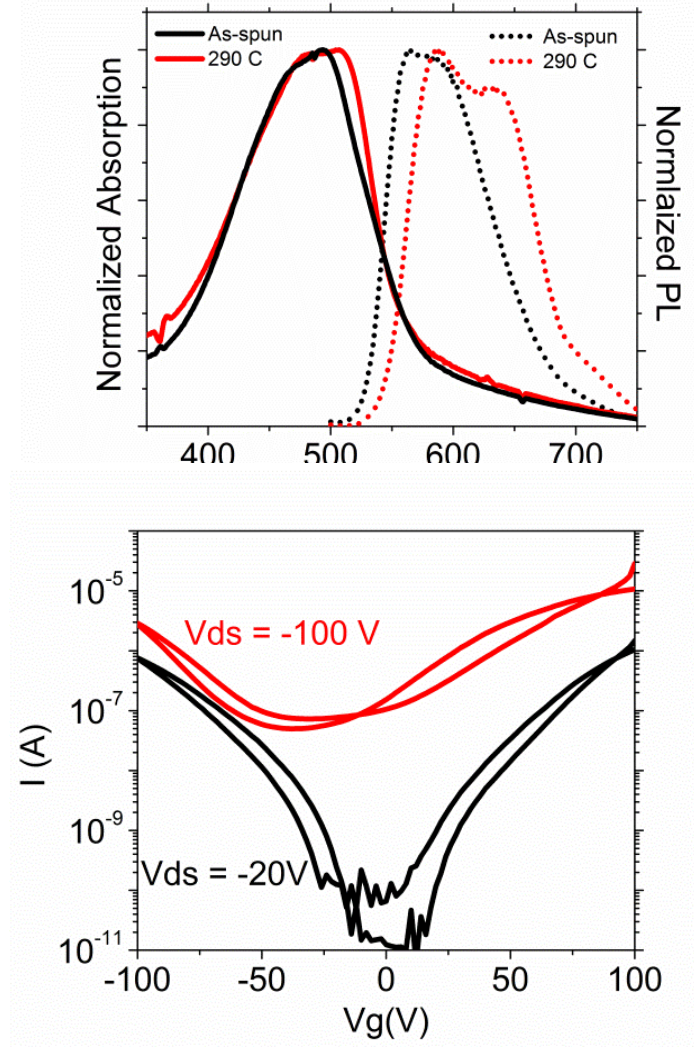
Figure 3. Top: Absorption and photoluminescence spectra of $\mathbf{P 2}$ thin film as-spun at $100{ }^{\circ} \mathrm{C}$ and annealed at $290{ }^{\circ} \mathrm{C}$ for 1 minute, excited at $501 \mathrm{~nm}, \mathrm{PLQE}=\sim 28 \%$. Bottom: Transfer characteristics of an LFET $(\mathrm{W}=1 \mathrm{~cm}, \mathrm{~L}=20 \mu \mathrm{m})$ based on P2 thin film annealed at $300{ }^{\circ} \mathrm{C}$.

In order to improve upon the molecular weight and final properties of $\mathbf{P 1}$, we opted for a longer $\mathrm{C}_{16}$ alkyl chain to improve solubility while maintaining the physical properties of the straight chain. While similar solubility problems were observed for $\mathbf{P 2}$ as in P1, the longer alkyl chain resulted in a modest $45 \%$ improvement in molecular weight yielding a $\mathrm{M}_{\mathrm{n}}$ of $9.4 \mathrm{~kg} / \mathrm{mol}$. The $\lambda_{\max }$ of $481 \mathrm{~nm}$ (Figure 1) for $\mathbf{P 2}$ is slightly $(6 \mathrm{~nm})$ red-shifted to $\mathbf{P 1}$ along with the optical band gap being slightly smaller at $2.24 \mathrm{eV}$, which can be attributed to the higher molecular weight. The luminescent properties of P2 also increased, showing a PLQE of $\sim 28 \%$ (Figure 3). P2 has a HOMO of $5.99 \mathrm{eV}$ and LUMO of $3.45 \mathrm{eV}$ (Figure S1 \& Table S2), which is very similar to the HOMO/LUMO levels of P1 (5.96/3.39 eV).

FETs fabricated from as-spun $\mathbf{P 2}$ had a hole mobility $\mu_{h}$ of $\sim 3 \times 10^{-4} \mathrm{~cm}^{2} \mathrm{~V}^{-1} \mathrm{~s}^{-1}$ and an electron mobility $\mu_{e}$ of $3 \times 10^{-3} \mathrm{~cm}^{2} \mathrm{~V}^{-1} \mathrm{~s}^{-}$ 1. While the hole mobility is quite similar to as-spun values for $\mathbf{P 1}$, the electron mobility is an order of magnitude lower. Upon annealing $\left(300^{\circ} \mathrm{C}\right), \mathbf{P} 2$ showed improved, but unbalanced ambipolar characteristics exhibiting a saturation hole mobility $\mu_{h} \sim 1.3 \mathrm{x}$ $10^{-3} \mathrm{~cm}^{2} \mathrm{~V}^{-1} \mathrm{~s}^{-1}$ and an electron mobility $\mu_{e}$ in the range of $1 \times 10^{-2} \mathrm{~cm}^{2} \mathrm{~V}^{-1} \mathrm{~s}^{-1}$ for devices of channel length $\mathrm{L}=20 \mu \mathrm{m}($ Figure $3 \&$ Table 1). While the hole mobility is on the same order of magnitude as in P1, the electron mobility increased an order of magnitude. One major reason for the improved electron mobility is the fact that this sample was annealed at $300{ }^{\circ} \mathrm{C}$ (unlike P1). XRD analysis of drop-cast films of $\mathbf{P 2}$ showed both first- and second-order diffraction maxima, with an increase in intensity of these peaks upon annealing, indicating an increase in order. An amorphous halo was seen at wider angles for both drop-cast and annealed films. Since P2 also shows the presence of end-groups (the stannyl end-groups can be seen at 0.43 ppm in the NMR spectra (Figure S5)), combined with an initial $2.7 \%$ weight loss (corresponding to the loss of end-groups) seen between $270-350{ }^{\circ} \mathrm{C}$ in the TGA (Figure S6), it is highly likely that some of these end-groups were cleaved off during the annealing process, which could be the cause of increased order and a higher electron mobility.

Table 1. Summary of OFET performance for devices using P1-P3 annealed at $300{ }^{\circ} \mathrm{C}$ for 30 minutes.

\begin{tabular}{|l|l|l|l|l|l|l|}
\hline Entry & $\begin{array}{l}\mu_{\mathrm{h}, \text { sat'd }} \\
\left(\mathrm{cm}^{2} / \mathrm{Vs}\right)\end{array}$ & $\begin{array}{l}\mu_{\mathrm{e}, \text { sat'd }} \\
\left(\mathrm{cm}^{2} / \mathrm{Vs}\right)\end{array}$ & $\begin{array}{l}\mathrm{I}_{\text {On }} / \mathrm{I}_{\text {off }} \\
(\mathrm{p}- \\
\text { type })\end{array}$ & $\begin{array}{l}\mathrm{I}_{\text {On }} / \mathrm{I}_{\text {off }} \\
(\mathrm{n}- \\
\text { type })\end{array}$ & $\begin{array}{l}\mathrm{V}_{\text {th, h }} \\
(\mathrm{V})\end{array}$ & $\begin{array}{l}\mathrm{V}_{\text {th, e- }} \\
(\mathrm{V})\end{array}$ \\
\hline P1 & $\sim 4 \times 10^{-3}$ & $\sim 2 \times 10^{-3}$ & $10^{4}$ & $10^{3}$ & -40 & +55 \\
\hline P2 & $\sim 1 \times 10^{-3}$ & $\sim 1 \times 10^{-2}$ & $10^{2}$ & $10^{3}$ & -66 & +31 \\
\hline P3 & $\sim 8 \times 10^{-5}$ & $\sim 1 \times 10^{-3}$ & $10^{4}$ & $10^{5}$ & -65 & +32 \\
\hline
\end{tabular}

\section{Polymers for NIR PLEDs}

Based on our initial work with the thiophene phthalimide copolymers discussed previously, which showed good ambipolar mobilities and PLQEs, we began to test these polymers as host materials for NIR PLEDs, starting with P3. While P3 has lower and unbalanced $\mu_{h}$ and $\mu_{e}$ mobilities, which will offer higher resistance in a PLED, due to its lack of order, it was thought that it's lack of crystallinity will help prevent aggregation of the NIR emitting segments and minimize host channels where the charges do not find the NIR segments. We chose two low gap DAD segments to use as the NIR emitters, one consisting of the bisthienyl(benzotriazolothiadiazole) (13) and the other consisting of the bisthienyl(thiadiazoloquinoxaline) (14) (Figure 1). The synthesis of DAD 14 (Figure 1) has been described previously in the literature. ${ }^{30}$ The synthesis of monomer 13 (Figure 1 \& Scheme S2) starts with the nitration of $\mathbf{8}^{31}$ with fuming nitric acid and trifluoromethanesulfonic acid to form $\mathbf{9}$ (41\%). Reduction of $\mathbf{9}$ with Fe powder in acetic acid yielded $\mathbf{1 0}(73 \%)$. Ring closure of $\mathbf{1 0}$ with N-thionylaniline yielded $\mathbf{1 1}(82 \%)$. Stille coupling of $\mathbf{1 1}$ with 2-tributylstannylthiophene yielded 12 (48\%). Bromination of 12 with NBS in DMF yielded the new DAD monomer 13 in $74 \%$ yield.

The synthesis of NIR emitting polymers P4-5 (Figure $1 \&$ Scheme S3) were carried out via Stille polymerization of phthalimide monomer 5, Bis(trimethylstannyl)thiophene (15) and the low gap DAD segments $\mathbf{1 3}$ or $\mathbf{1 4}$. After polymerization the polymers were precipitated into methanol $(\mathrm{MeOH})$, collected by filtration, dissolved in $\sim 100 \mathrm{~mL}$ of chloroform (CF) and stirred vigorously with sodium diethyldithiocarbamate trihydrate $\left(\sim 5 \mathrm{~g}\right.$ in $\left.100 \mathrm{~mL} \mathrm{H} \mathrm{H}_{2} \mathrm{O}\right)$ overnight to remove any residual catalyst. Then the $\mathrm{CF} / \mathrm{polymer}$ solution was washed with water $(3 \mathrm{X})$, concentrated, precipitated into $\mathrm{MeOH}$ and collected by filtration. The polymer was then subjected to Soxhlet extraction with $\mathrm{MeOH}$, acetone, hexane and $\mathrm{CF}$. The $\mathrm{CF}$ fraction was concentrated, precipitated into MeOH and a light golden-brown solid was collected by filtration for P4 and P5. Both polymers obtained were of high molecular weight, 42 $\mathrm{kg} / \mathrm{mole}(\mathbf{P 4})$ and $92 \mathrm{~kg} / \mathrm{mol}(\mathbf{P 5})$, and high thermal stability $\left(1 \%\right.$ weight loss $>430{ }^{\circ} \mathrm{C}$. Only $1 \mathrm{~mol} \%$ of the low gap DAD emitters 
(relative to $\mathbf{1 5}$, based on the initial feed ratios) were used in these polymers since we have shown these loadings to yield the most efficient NIR OLEDs while limiting concentration quenching. ${ }^{18}$ Incorporation of the DAD segment can be seen in the low energy portion of the UV-Vis-NIR spectra (Figure 1). P4, using the slightly weaker benzotriazolothiadiazole based emitter, has a $\lambda$ max of $\sim 785 \mathrm{~nm}$ with an onset of absorption at $907 \mathrm{~nm}$, corresponding to an optical band gap of $1.37 \mathrm{eV}$. Meanwhile, P5, using the stronger thiadiazoloquinoxaline based emitter, has a $\lambda_{\max }$ of $\sim 795 \mathrm{~nm}$ with an onset of absorption at $987 \mathrm{~nm}$, corresponding to an optical band gap of $1.26 \mathrm{eV}$. Both polymers have a high energy peak attributed to the high gap phthalimide-thiophene polymer host at $441 \mathrm{~nm}$ (P4) and $439 \mathrm{~nm}$ (P5).

a)

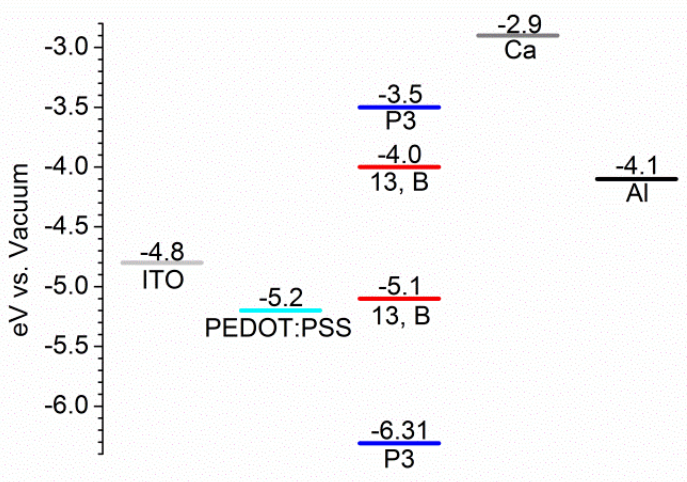

c)

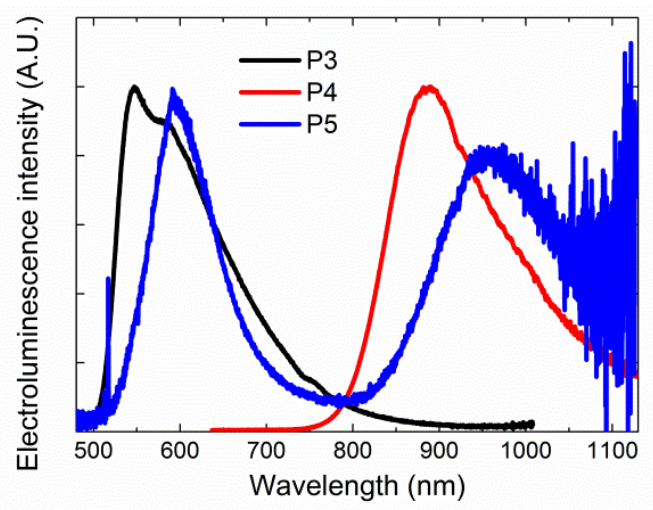

b)

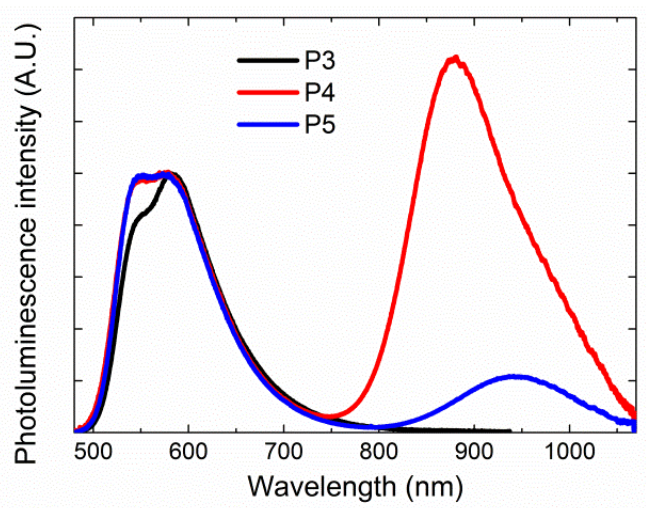

d)

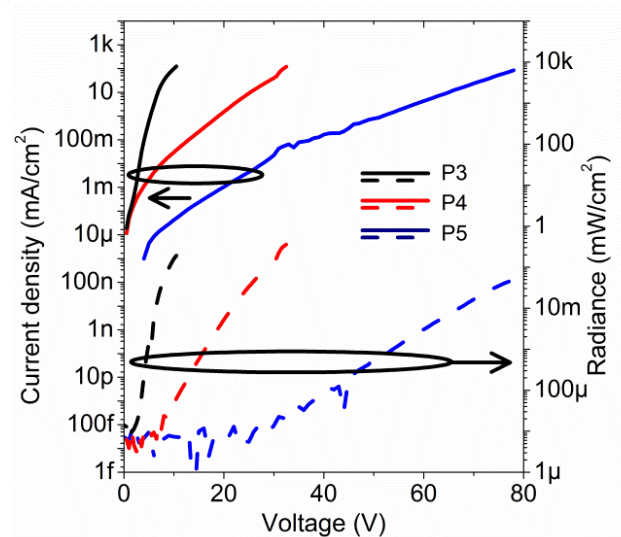

Figure 4. (a) HOMO/LUMO levels for P3-5 and the device architecture used in this study. HOMO/LUMO levels for the DAD unit in $\mathbf{P} 4^{[26]}$ and $\mathbf{P 5}^{[28]}$ were based on literature for similarly structured compounds. (b) Normalized photoluminescence spectra for polymers P3-5. (c) Normalized electroluminescence spectra for polymers P3-5. (d) Typical current/voltage and light/voltage curves for polymers P3, P4 and P5.

Table 2. Summary of PLED device performance for P3-5.

\begin{tabular}{|l|l|l|l|l|l|l|l|}
\hline Polymer & $\begin{array}{l}\text { NIR PL peak } \\
(\mathrm{nm})\end{array}$ & $\%$ PL in NIR & $\begin{array}{l}\text { NIR EL peak } \\
(\mathrm{nm})\end{array}$ & $\%$ EL in NIR & Max. EQE $(\%)$ & V $_{\text {on }}($ light, V) & $\begin{array}{l}\text { Max. light } \\
\left(\mathrm{mW} / \mathrm{cm}^{2}\right)\end{array}$ \\
\hline P3 & - & 6 & - & 15 & $0.09 \pm 0.02$ & $4.1 \pm 0.3$ & $0.19 \pm 0.03$ \\
\hline P4 & $\mathbf{8 8 0}$ & $\mathbf{6 4}$ & $\mathbf{8 8 5}$ & $\mathbf{9 9 . 8}$ & $\mathbf{0 . 2 7} \pm \mathbf{0 . 0 1}$ & $\mathbf{1 1 . 1} \pm \mathbf{0 . 7}$ & $\mathbf{0 . 3 6} \pm \mathbf{0 . 1 3}$ \\
\hline P5 & 940 & 24 & 955 & 63 & $0.046 \pm 0.01$ & $40 \pm 4$ & $0.04 \pm 0.01$ \\
\hline
\end{tabular}

[a] NIR defined as $\lambda>700 \mathrm{~nm}$.

In this study square-wave voltammetry was used to determine the HOMO/LUMO levels of the polymers (Figure S1 \& Table S2). P3 has a HOMO of 6.31 eV and LUMO of $3.50 \mathrm{eV}$ (Figure 4). Due to the small loadings of the DAD segments, square-wave voltammetry of polymers $\mathbf{P 4}$ and $\mathbf{P 5}$ show no signal from the low gap DAD segments, and look identical to P3. However, based on previous studies of similarly structured compounds in the literature, we estimated the HOMO/LUMO positions of these DAD segments to be $\sim-5.1 /-4.0 \pm 0.1 \mathrm{eV}$ for both segment $14^{28}$ and $13 .{ }^{26}$ Since the HOMO/LUMO levels of these DAD segments lie within the HOMO/LUMO levels the host polymer P3 (Figure 4), this should allow for charge and energy transfer to the DAD segments in the PLED devices. ${ }^{32}$

Photoluminescence (PL) spectra can be seen in Figure 4. In both cases there is PL emission from the host portion of the polymer; however $\mathbf{P 5}$ has much more emission from the host relative to the DAD emission (76:24) while P4 has more emission from the DAD 
segment than the host (64:36). In both cases, this indicates that energy transfer to the DAD moiety is not complete, which we attribute to the somewhat limited spectral overlap between the emission of P3 and absorption of the DAD moiety in P4, and to a greater extent in P5.

PLEDs were prepared with the structure glass / ITO / PEDOT:PSS / (P3, P4 or P5) / Ca / Al according to the procedure outlined in the Supplementary Information. Electroluminescence (EL) spectra and current-voltage-light characteristics of the devices can be seen in Figure 4, and the data is summarized in Table 2. PLEDs made from the host polymer (P3) have a broad yellow emission peaking at $\sim 547 \mathrm{~nm}(\sim 584 \mathrm{~nm}$ shoulder $)$ tailing off into the NIR just beyond $800 \mathrm{~nm}$. For P4, this visible emission from the host is completely quenched, with a single emission peak at $885 \mathrm{~nm}$, just $5 \mathrm{~nm}$ red-shifted relative to the PL peak. $99.8 \%$ of the emission is in the NIR region (>700 nm) and there is no detectable emission coming from the host emitter. The better spectral purity obtained in EL vs. PL is relatively common and this 'energy selective' process has been described previously as due to the migration of charges in the devices onto lower energy (DAD) sites and direct exciton formation on these sites. ${ }^{18,33}$ This charge trapping on lowenergy sites makes it possible to obtain significant emission from the NIR dopant without having to rely on energy transfer from the host donors. Devices with P5, showed EL further into the NIR, peaking at $955 \mathrm{~nm}$, but did not exhibit such spectral purity with 37 $\%$ of the EL emission coming from the host polymer. Although there is proportionally less residual host emission than in the PL spectrum, these devices clearly suffer from the low overlap of the host emission with the DAD absorption noted earlier. It is also worth noting that although the proportion of excitons formed on (or transferred to) DAD 14 in P5 may be somewhat higher than 63 $\%$, the lower quantum efficiency of emission from DAD 14 compared to the host acts to reduce the proportion of emission from the DAD. Furthermore, DAD 14's larger size than DAD 13 may result in a polymer morphology for P5 that disfavors charge and energy transfer to DAD 14.

For the host polymer P3, an EL efficiency of $0.09 \pm 0.02 \%$ was obtained with a maximum radiance of $0.19 \mathrm{~mW} / \mathrm{cm}^{2}$ and a turnon voltage of 4.1 V. Upon addition of the DAD segment 13 and $\mathbf{1 4}$ in P4 and P5, the turn-on voltage increases up to $11.1 \mathrm{~V}$ and 40.0 $\mathrm{V}$ respectively. This is most likely due to charge trapping on the DAD segments, as a result of a lack of a percolation network on these moieties at a loading of just $1 \%$. The best performing NIR PLED devices were made from P4 emitting at $885 \mathrm{~nm}$. An EL efficiency of $0.27 \pm 0.01 \%$ was obtained with a maximum radiance of $0.36 \mathrm{~mW} / \mathrm{cm}^{2}$. In terms of EQE, this is the best result reported in the literature to date for a pure, unblended single layer polymer emitter at such a long wavelength. ${ }^{21,23}$ NIR PLED devices made from $\mathbf{P 5}$ emit at $955 \mathrm{~nm}$ and have a maximum EQE of $0.046 \pm 0.01 \%$. The lower quantum efficiency relative to P4 is expected from increased vibrational coupling for lower gap emitters, but, nonetheless, P5 equals the most efficient PLED to date in the $>950$ nm region. ${ }^{23}$ Also worth noting is the much higher turn-on voltage (40 V) compared to P4 (11 V). It is possible that the larger size of DAD 14 relative to $\mathbf{1 3}$ could cause quite different morphologies that may disfavor the transport of at least one charge carrier in P5, which is already unbalanced by $\sim 1$ order of magnitude in favor of electron mobility verses holes based on FET data (Table 1).

\section{Conclusion}

In summary, a family of phthalimide-thiophene copolymers with various alkyl-chain substitutions, which resulted in quite a difference in their physical and optoelectronic properties, have proven to be quite useful as LEFET materials. Even though polymers $\mathbf{P 1}$ and $\mathbf{P 2}$ are much lower in molecular weight and possess stannyl end-groups when compared to P3, they are significantly more emissive (PLQE of 20 and $28 \%$ versus $3 \%$ ) and performed better in LEFETs. P1 showed the best ambipolar behavior with saturated hole and electron mobilities of $\mu_{h} \sim 4 \times 10^{-3} \mathrm{~cm}^{2} \mathrm{~V}^{-1} \mathrm{~s}^{-1}$ and $\mu_{e} \sim 2 \times 10^{-3} \mathrm{~cm}^{2} \mathrm{~V}^{-1} \mathrm{~s}^{-1}$ respectively, and an overall EQE up to $0.2 \%$ in LEFETs having a broad emission peaking at $580 \mathrm{~nm}$ with a $640 \mathrm{~nm}$ shoulder. Meanwhile, P2 had a more unbalanced ambipolar behavior with a higher electron mobility $\left.\mu_{e} \sim 1 \times 10^{-2} \mathrm{~cm}^{2} \mathrm{~V}^{-1} \mathrm{~s}^{-1}\right)$, but a similar hole mobility $\left(\mu_{h} \sim 1.3 \times 10^{-3} \mathrm{~cm}^{2} \mathrm{~V}^{-1} \mathrm{~s}^{-1}\right)$ to P1, while emitting in the same region. The lower efficiency of the LEFETs with P1-3 relative to F8BT can be explained by the unbalanced mobilities and that these materials are less emissive. The fact that copolymers P1-3 did demonstrate reasonable PLQEs in the solid state and ambipolar mobility led to further investigation of these materials as hosts in NIR PLEDs.

So far the novel phthalimide-thiophene copolymer P3 has proven to be a good host material for NIR PLEDs, and that the copolymerization approach to achieving polymer electroluminescence in the range of $900 \mathrm{~nm}$ continues to be an effective strate gy. Using only $1 \%$ loading of the novel low gap bisthienyl(benzotriazolothiadiazole) DAD unit 13, efficiencies of $0.27 \%$ were measured with peak emission at $885 \mathrm{~nm}$, confirming this is the best performing single layer pure polymer system to date. Based on our LEFET results, this system has the ability to be optimized even further by using the higher mobility, and much higher emissive materials based on P1 or P2. These materials will also offer better spectral overlap since they are red-shifted relative to P3. Due to the simple device architecture used in this study, charge injection and efficiencies could also be further optimized by adding a hole blocking layer such as TFB or an electron blocking layer and by improving the light out-coupling. Further studies are on-going looking in to the use of $\mathbf{P 1}$ or $\mathbf{P 2}$ based host polymers for their high (ambipolar) mobilities combined with DAD 13 and other NIR emitters in polymer LEDs.

\section{Acknowledgements}


The authors would like to thank the European Community's Seventh Framework Programme (FP7/2007-2013) under grant agreement $\mathrm{n}^{\circ} 212311$ of the ONE-P project and Chalmers Areas of Advance, Materials Science for funding. The authors would also like to thank Patrik Henriksson for the electrochemical measurements, Anders Mårtensson for GPC measurements and Volodymyr Kuzmenko for XRD measurements.

\section{Notes and references}

${ }^{a}$ Department of Chemical and Biological Engineering

Chalmers University of Technology

SE-412 96 Gothenburg, Sweden

E-mail: mats.andersson@chalmers.se

${ }^{b}$ Cavendish Laboratory

University of Cambridge

J. J. Thomson Avenue

Cambridge, CB3 OHE

E-mail: hs220@cam.ac.uk

${ }^{c}$ Department of Physics and Astronomy (CMMP Group) and

London Centre for Nanotechnology

University College London

Gower Street

London, WC1E 6BT

E-mail: f.cacialli@ucl.ac.uk

+ These authors contributed equally to this work.

'Present address: School of Advanced Materials Engineering, Kookmin University, Seoul, 136-702, Korea

${ }^{[\S]}$ Present address: Laboratoire de Physique et d'Etude des Matériaux, ESPCI/CNRS/Université Pierre et Marie Curie, UMR 8213 , 10 Rue Vauquelin, 75005 Paris, France

${ }^{[\ddagger]}$ Present address: Institut de Science et d'Ingénierie Supramoléculaires (I.S.I.S.), Université de Strasbourg, 8, allée Gaspard Monge, Strasbourg, Alsace, 67000, France

$\dagger$ Electronic Supplementary Information (ESI) available: Synthetic details and materials characterization]. See DOI: 10.1039/b000000x/

1 M. Shahid, T. McCarthy-Ward, J. Labram, S. Rossbauer, E. B. Domingo, S. E. Watkins, N. Stingelin, T. D. Anthopoulos, M. Heeney, Chem. Sci, 2012, 3, 181; H.-W. Lin, W.-Y. Lee, W.-C. Chen, J. Mat. Chem., 2012, 22, 2120; H. Bronstein, Z. Chen, R. S. Ashraf, W. Zhang, J. Du, J. R. Durrant, P. Shakya Tuladhar, K. Song, S. E. Watkins, Y. Geerts, M. M. Wienk, R. A. J. Janssen, T. Anthopoulos, H. Sirringhaus, M. Heeney, I. McCulloch, J. Am. Chem. Soc. 2011, 133, 3272.

2 K.-J. Baeg, D. Khim, S.-W. Jung, M. Kang, I.-K. You, D.-Y. Kim, A. Facchetti, Y.-Y. Noh, Advanced Materials, 2012, 24, 5433; A. Facchetti, Chemistry of Materials 2011, 23, 733; X. Zhang, T. T. Steckler, R. R. Dasari, S. Ohira, W. J. Potscavage Jr, S. P. Tiwari, S. Coppee, S. Ellinger, S. Barlow, J.-L. Bredas, B. Kippelen, J. R. Reynolds, S. R. Marder, J. Mat. Chem., 2010, 20, 123.

3 C. Zhong, C. Duan, F. Huang, H. Wu, Y. Cao, Chem. Mater., 2011, 23, 326.

4 A. Duarte, K.-Y. Pu, B. Liu, G. C. Bazan, Chem. of Mater., 2010, 23, 501; H. Wu, L. Ying, W. Yang, Y. Cao, Chem. Soc. Rev., 2009, 38, 3391; J. H. Burroughes, D. D. C. Bradley, A. R. Brown, R. N. Marks, K. Mackay, R. H. Friend, P. L. Burns, A. B. Holmes, Nature, 1990, 347, 539; H. Christian-Pandya, S. Vaidyanathan, M. Galvin, Polymers for Use in Polymeric Light-Emitting Diodes: Structure-Property Relationships. In Conjugated Polym.: Process. Appl. T. A. Skotheim and J. R. Reynolds, eds.; CRC Press: Boca Raton, 2007; pp 5-3-5-35.

5 W. Brütting, J. Frischeisen, B. J. Scholz, T. D. Schmidt, Europhys. News, 2011, 42, 20.

6 E. J. Meijer, D. M. de Leeuw, S. Setayesh, E. van Veenendaal, B. H. Huisman, P. W. M. Blom, J. C. Hummelen, U. Scherf, T. M. Klapwijk, Nature Mater., 2003, 2, 678; B. Crone, A. Dodabalapur, Y. Y. Lin, R. W. Filas, Z. Bao, A. LaDuca, R. Sarpeshkar, H. E. Katz, W. Li, Nature, 2000, 403, 521.

7 H. N. Tsao, D. M. Cho, I. Park, M. R. Hansen, A. Mavrinskiy, D. Y. Yoon, R. Graf, W. Pisula, H. W. Spiess, K. Müllen, J. Am. Chem. Soc., 2011, 133, 2605; T. Lei, J.-H. Dou, Z.-J. Ma, C.-H. Yao, C.-J. Liu, J.-Y. Wang, J. Pei, J. Am. Chem. Soc., 2012, 134, 20025; J. S. Ha, K. H. Kim, D. H. Choi, J. Am. Chem. Soc., 2011, 133, 10364; J. Fan, J. D. Yuen, W. Cui, J. Seifter, A. R. Mohebbi, M. Wang, H. Zhou, A. Heeger, F. Wudl, Adv. Mater., 2012, 24, 6164; H. Chen, Y. Guo, G. Yu, Y. Zhao, J. Zhang, D. Gao, H. Liu, Y. Liu, Adv. Mater., 2012, 24, 4618.

8 J. Lee, A. R. Han, J. Kim, Y. Kim, J. H. Oh, C. Yang, J. Am. Chem. Soc., 2012, 134, 20713.

9 X. Guo, F. S. Kim, S. A. Jenekhe, M. D. Watson, J. Am. Chem. Soc., 2009, 131, 7206.

10 J. Zaumseil, C. R. McNeill, M. Bird, D. L. Smith, P. P. Ruden, M. Roberts, M. J. McKiernan, R. H. Friend, H. Sirringhaus, J. Appl. Phys. 2008, 103, 064517.

11 J. Zaumseil, C. L. Donley, J. S. Kim, R. H. Friend, H. Sirringhaus, Adv. Mater., 2006, 18, 2708.

12 B. B. Y. Hsu, C. Duan, E. B. Namdas, A. Gutacker, J. D. Yuen, F. Huang, Y. Cao, G. C. Bazan, I. D. W. Samuel, A. J. Heeger, Adv. Mater., 2012, 24, 1171; J. Zaumseil, R. H. Friend, H. Sirringhaus, Nature Mater., 2006, 5, 69. 
13 M. C. Gwinner, D. Kabra, M. Roberts, T. J. K. Brenner, B. H. Wallikewitz, C. R. McNeill, R. H. Friend, H. Sirringhaus, Adv. Mater., 2012, 24, 2728.

14 A. Hepp, H. Heil, W. Weise, M. Ahles, R. Schmechel, H. von Seggern, Phys. Rev. Lett., 2003, 91, 157406.

15 L. Bürgi, M. Turbiez, R. Pfeiffer, F. Bienewald, H.-J. Kirner, C. Winnewisser, Adv. Mater., 2008, $20,2217$.

16 M. C. Gwinner, T. J. K. Brenner, J.-K. Lee, C. Newby, C. K. Ober, C. R. McNeill, H. Sirringhaus, J. Mater. Chem., 2012, 22, 4436; J. H. Seo, E. B. Namdas, A. Gutacker, A. J. Heeger, G. C. Bazan, Appl. Phys. Lett., 2010, 97, 043303; R. Capelli, S. Toffanin, G. Generali, H. Usta, A. Facchetti, M. Muccini, Nature Mater., 2010, 9, 496; E. C. P. Smits, S. Setayesh, T. D. Anthopoulos, M. Buechel, W. Nijssen, R. Coehoorn, P. W. M. Blom, B. de Boer, D. M. de Leeuw, Adv. Mater., 2007, 19, 734; F. Cicoira, C. Santato, Adv. Funct. Mater., 2007, 17, 3421; J. S. Swensen, C. Soci, A. J. Heeger, Appl. Phys. Lett., 2005, 87, 253511.

17 M. C. Gwinner, S. Khodabakhsh, H. Giessen, H. Sirringhaus, Chem. Mater., 2009, 21, 4425.

18 T. T. Steckler, O. Fenwick, T. Lockwood, M. R. Andersson, F. Cacialli, Macromol. Rapid Commun., 2013, 34, 990. O. Fenwick, S. Fusco, T. N. Baig, F. Di Stasio, T. T. Steckler, P. Henriksson, C. Flechon, M. R. Andersson, F. Cacialli, APL Materials, $2013,1,032108$.

19 G. M. Farinola, R. Ragni, Chem. Soc. Rev., 2011, 40, 3467.

20 K. R. Graham, Y. Yang, J. R. Sommer, A. H. Shelton, K. S. Schanze, J. Xue, J. R. Reynolds, Chem. Mater., 2011, 23, 5305; Y. Yang, R. T. Farley, T. T. Steckler, S.-H. Eom, J. R. Reynolds, K. S. Schanze, J. Xue, J. Appl. Phys., 2009, 106, 044509; Q. Gang, Z. Ze, L. Min, Y. Dengbin, Z. Zhiqiang, W. Zhi Yuan, M. Dongge, Adv. Mater., 2009, 21, 111; O. Fenwick, J. K. Sprafke, J. Binas, D. V. Kondratuk, F. Di Stasio, H. L. Anderson, F. Cacialli, Nano Lett., 2011, 11, 2451.

21 P. Li, O. Fenwick, S. Yilmaz, D. Breusov, D. J. Caruana, S. Allard, U. Scherf, F. Cacialli, Chem. Commun., 2011, 47, 8820.

22 G. Tzamalis, V. Lemaur, F. Karlsson, P. O. Holtz, M. Andersson, X. Crispin, J. Cornil, M. Berggren, Chem. Phys. Lett., 2010, 489, 92; A. Gadisa, E. Perzon, M. R. Andersson, O. Inganas, Appl. Phys. Lett., 2007, 90, 113510; Y. Xia, J. Luo, X. Deng, X. Li, D. Li, X. Zhu, W. Yang, Y. Cao, Macromol. Chem. Phys., 2006, 207, 511; Z. Yong, Y. Jian, H. Qiong, M. Yueqi, P. Junbiao, C. Yong, Chin. Sci. Bull., 2005, 50, 957; R. Yang, R. Tian, J. Yan, Y. Zhang, J. Yang, Q. Hou, W. Yang, C. Zhang, Y. Cao, Macromolecules, 2005, 38, 244; B. C. Thompson, L. G. Madrigal, M. R. Pinto, T.-S. Kang, K. S. Schanze, J. R. Reynolds, J. Polym. Sci., Part A: Polym. Chem., 2005, 43, 1417.

23 M. Chen, E. Perzon, M. R. Andersson, S. Marcinkevicius, S. K. M. Jonsson, M. Fahlman, M. Berggren, Appl. Phys. Lett., $2004,84,3570$.

24 M. Sun, X. Jiang, W. Liu, T. Zhu, F. Huang, Y. Cao, Synth. Met., 2012, 162, 1406.

25 T. L. Tam, H. Li, Y. M. Lam, S. G. Mhaisalkar, A. C. Grimsdale, Org. Lett., 2011, 13, 4612.

26 D. G. Patel, F. Feng, Y.-y. Ohnishi, K. A. Abboud, S. Hirata, K. S. Schanze, J. R. Reynolds, J. Am. Chem. Soc., 2012, $134,2599$.

27 L. Yingliang, C. Huayu, L. Jianghui, C. Zhijian, C. Shaokui, X. Lixin, X. Shengang, G. Qihuang, J. Polym. Sci., Part A: Polym. Chem., 2007, 45, 4867; A. Tanimoto, T. Yamamoto, Adv. Synth. Catal., 2004, 346, 1818.

28 S. Hellstrom, F. Zhang, O. Inganas, M. R. Andersson, Dalton Trans., 2009, 45, 10032.

29 Z. Chen, J. Fang, F. Gao, T. J. K. Brenner, K. K. Banger, X. Wang, W. T. S. Huck, H. Sirringhaus, Org. Electron., $2011,12,461$.

30 E. Perzon, F. Zhang, M. Andersson, W. Mammo, O. Inganäs, M. R. Andersson, Adv. Mater., 2007, 19, 3308.

31 V. Murugesan, R. de Bettignies, R. Mercier, S. Guillerez, L. Perrin, Synth. Met., 2012, 162, 1037.

32 X. Gong, J. C. Ostrowski, D. Moses, G. C. Bazan, A. J. Heeger, Adv. Funct. Mater., 2003, 13, 439; V. Cleave, G. Yahioglu, P. Le Barny, D. H. Hwang, A. B. Holmes, R. H. Friend, N. Tessler, Adv. Mater., 2001, 13, 44; W. Chung-Chih, J. C. Sturm, R. A. Register, T. Jing, E. P. Dana, M. E. Thompson, IEEE Trans. Electron Devices, 1997, 44, 1269.

33 D. Cao, Q. Liu, W. Zeng, S. Han, J. Peng, S. Liu, Macromolecules, 2006, 39, 8347.

34 J. C. de Mello, H. F. Wittmann, R. H. Friend, Adv. Mater., 1997, 9, 230.

35 G.-y. Chen, S.-c. Lan, P.-y. Lin, C.-w. Chu, K.-h. Wei, J. Polym. Sci., Part A: Polym. Chem., 2010, 48, 4456. 